\title{
Denosumab in the Treatment of Osteoporosis: 10 Years Later: A Narrative Review
}

\author{
David L. Kendler · Felicia Cosman · Robert Kees Stad · \\ Serge Ferrari
}

Received: April 27, 2021 / Accepted: September 27, 2021 / Published online: November 11, 2021

(C) The Author(s) 2021

\section{ABSTRACT}

The fully human monoclonal antibody denosumab was approved for treatment of osteoporosis in 2010 on the basis of its potent antiresorptive activity, which produces clinically meaningful increases in bone mineral density (BMD) and reduces fracture risk at key skeletal sites. At that time, questions remained regarding the long-term safety and efficacy of this receptor activator of nuclear factor kappa-B

Digital Features This article is published with digital features, including a video, to facilitate understanding of the article. To view digital features for this article go to https://doi.org/10.6084/m9.figshare.16723372.

Supplementary Information The online version contains supplementary material available at https:// doi.org/10.1007/s12325-021-01936-y.

D. L. Kendler ( $\square)$

Department of Medicine, University of British

Columbia, Vancouver, BC, Canada

e-mail: davidkendler@gmail.com

F. Cosman

Department of Medicine, Columbia University,

New York, NY, USA

R. K. Stad

Amgen Inc., Rotkreuz, Switzerland

S. Ferrari

Division of Bone Diseases, Geneva University

Hospitals, Geneva, Switzerland ligand (RANKL) inhibitor; and with clinical experience, new questions have arisen regarding its optimal use. Here, we examine these questions through the lens of data from the FREEDOM trial program and other studies to determine where denosumab fits in the osteoporosis treatment landscape. Clinical consensus and evidentiary support have grown for denosumab as a highly effective anti-osteoporosis therapy for patients at high risk of fracture. In the 10-year FREEDOM Extension study, denosumab treatment produced progressive incremental increases in BMD, sustained low rates of vertebral fracture, and further reduction in nonvertebral fracture risk without increased risk of infection, cancer, or immunogenicity. There was no evidence that suppression of bone turnover or mineralization was excessive, and rates of osteonecrosis of the jaw (ONJ) and atypical femoral fracture (AFF) were very low. It is now recognized, however, that transitioning to another anti-osteoporosis therapy after denosumab discontinuation is essential to mitigate a transient rebound of bone turnover causing rapid BMD loss and increased risk of multiple vertebral fractures (MVFs). Taken together, the available data show that denosumab has a favorable benefit/risk profile and is a versatile agent for preventing osteoporotic fractures in the short and long term. 
Keywords: Osteoporosis; Bone density; Endocrinology; Orthopedics; Therapeutics; General medicine

\section{Key Summary Points}

Despite the availability of safe and effective anti-osteoporosis therapies, osteoporosis continues to be underdiagnosed and undertreated.

Denosumab is a potent antiresorptive medication for treatment of osteoporosis, with clinical trial data for up to 10 years of treatment that demonstrate its safety and efficacy in reducing fracture risk.

The continued gain in bone density differentiates denosumab from bisphosphonates, for which there is generally a plateau in hip bone mineral density after 3-4 years of treatment. Despite aging of the study population, non-vertebral fracture rates upon 4-10 years of treatment with denosumab were lower than initially observed with 3 years of therapy.

Long-term bone turnover inhibition with denosumab treatment for up to 10 years demonstrated a favorable benefit/risk profile when comparing fractures prevented per skeletal adverse event (e.g., osteonecrosis of the jaw and atypical femoral fracture) observed. Furthermore, the subject incidence of adverse events, including infection and malignancy, remained low over time in the aging study population.

If denosumab therapy is discontinued, transition to a different class of antiosteoporosis medication, such as a bisphosphonate, can help prevent complete loss of the BMD gained with denosumab and maintain anti-fracture efficacy.

\section{INTRODUCTION}

Osteoporosis-a chronic and progressive disease in which excessive bone loss weakens the skeleton over time-has long been underdiagnosed and undertreated [1]. Over the last two decades, this persistent treatment gap has sparked innovations in pharmacologic therapy, with varied goals such as offering alternative mechanisms of action (MOAs); improving adherence and persistence to treatment; attaining greater increases in bone mineral density (BMD); achieving faster, greater, progressive reductions in fracture risk; and improving access through lower-cost generic formulations [2, 3].

In 1997, researchers identified the protein osteoprotegerin, which regulates bone resorption by acting as a "decoy" to receptor activator of nuclear factor kappa-B ligand (RANKL), thus preventing receptor activation of RANK expressed on osteoclasts and precursor cells [4]. This discovery led to the development of denosumab, a fully human monoclonal antibody that also binds RANKL to block RANK activation but has a longer half-life and more potent antiresorptive activity than osteoprotegerin [5]. Denosumab $60 \mathrm{mg}$ administered as a subcutaneous injection every 6 months (Q6M) prevents osteoclast-mediated bone resorption (i.e., bone loss), reducing the risk of osteoporotic fracture. It is the first and only RANKL inhibitor to receive regulatory approval and the first antibody therapy approved for treatment of postmenopausal osteoporosis, receiving initial marketing authorizations under the brand name Prolia ${ }^{\circledR}$ (manufactured by Amgen, Thousand Oaks, CA) in the USA, the European Union, and other regions in 2010 [6-8]. Denosumab was later approved for treatment of osteoporosis in men, glucocorticoid-induced osteoporosis, and bone loss due to aromatase inhibitor or androgen deprivation cancer therapies [9].

Despite the recent innovations in pharmacologic therapy, underdiagnosis and undertreatment of osteoporosis persist because of under-recognition of the disease's prevalence, focus on other healthcare priorities, and a 
lack of processes within many healthcare systems to identify patients at risk of osteoporosis. Concerns about rare side effects of antiresorptive therapies, such as osteonecrosis of the jaw (ONJ) and atypical femoral fracture (AFF), have also contributed to underutilization of osteoporosis medication, although data continue to demonstrate that the benefits of osteoporosis therapy far outweigh the risks in patients at high risk of fracture.

\section{The FREEDOM Trial}

In the pivotal 3-year FREEDOM trial (Fig. 1), the relative risk of fracture in subjects receiving denosumab was reduced $68 \%, 40 \%, 20 \%$, and $16 \%$ for radiographic vertebral, hip, nonvertebral, and wrist fractures, respectively, compared with placebo $[10,11]$. Denosumab also increased BMD at the lumbar spine, total hip, femoral neck, and radius and decreased serum bone turnover markers (BTMs), consistent with its mechanism of action [11, 12]. The BMD gains observed with denosumab are clinically relevant because they explain about half of the risk reduction for new vertebral fractures and most of the risk reduction for nonvertebral fractures [13]. Risk of delayed fracture healing or non-union was very low and similar in denosumab-treated subjects (2/303) versus untreated controls (6/364), and no subjects who received denosumab in the 6 weeks before or after the fracture experienced these complications [14]. FREEDOM and other studies showed similar efficacy and safety of denosumab between subjects with and without mild-to-moderate chronic kidney disease (stages 1-3), suggesting denosumab is generally well tolerated in patients with aging-associated reduced renal function, although these patients should be monitored for hypocalcemia [15-17]. No cases of ONJ or AFF were observed during FREEDOM, and overall rates of adverse events (AEs) or discontinuation due to AEs were not significantly different between treatment groups.

Although FREEDOM demonstrated that denosumab is safe and effective for up to 3 years of treatment, at the time of marketing authorization questions remained about the long-

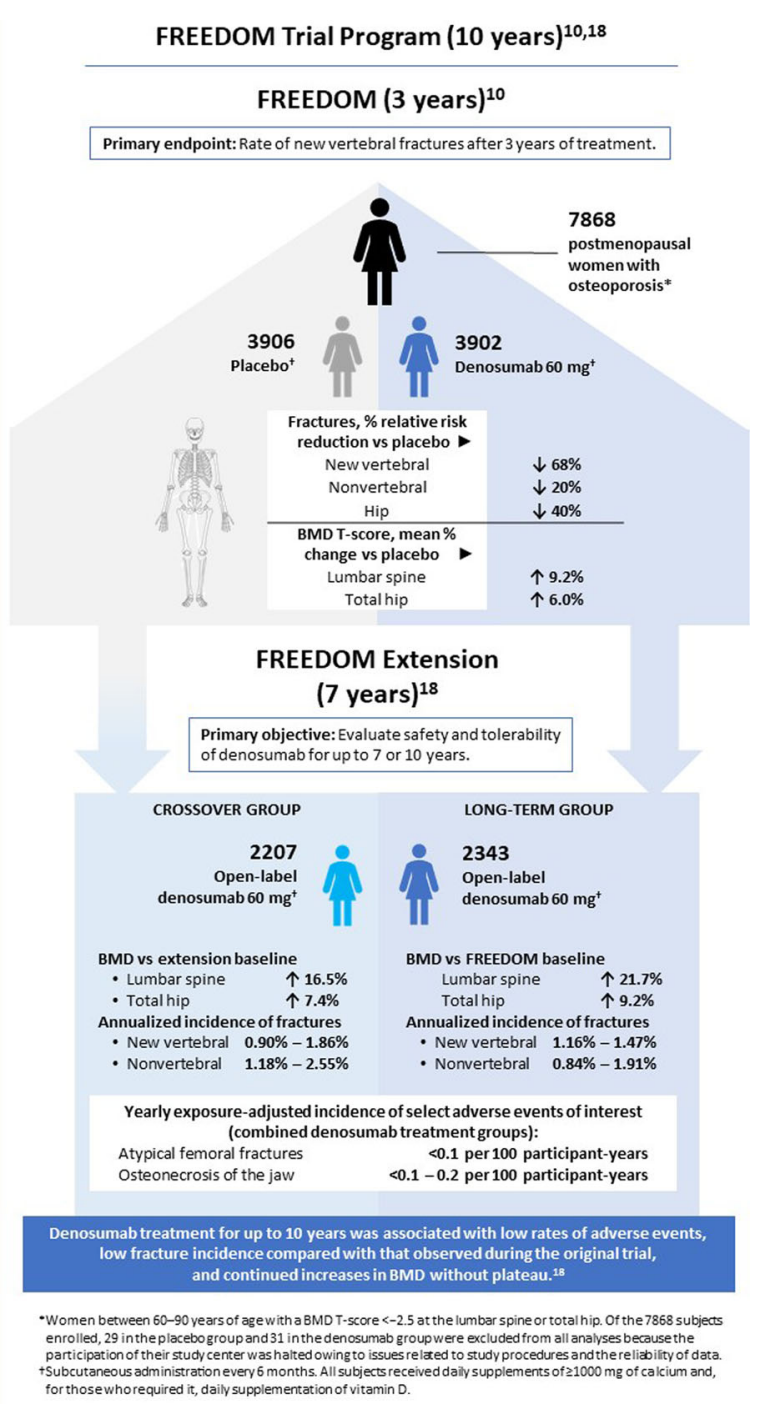

Fig. 1 Graphical summary of FREEDOM and FREEDOM Extension data. The primary endpoint of the 3-year FREEDOM trial in women with postmenopausal osteoporosis was the rate of new vertebral fractures over 3 years. All subjects who completed that trial without discontinuing treatment or missing more than one dose of either denosumab or placebo were eligible to enroll in the openlabel, 7-year FREEDOM Extension, in which all participants received denosumab. Patients formerly in the placebo group were enrolled in the "crossover group," whereas those who had received denosumab continued on denosumab as the "long-term group." The primary objective of FREEDOM Extension was to evaluate the safety and tolerability of denosumab for up to 7 (crossover group) or 10 (long-term group) years of treatment 
term impact of RANKL inhibition, including its effectiveness at increasing BMD and decreasing fracture risk over the long term; its safety in terms of long-term bone turnover suppression and potential immunologic effects; and the reversibility of its antiresorptive activity. Over time, additional questions have emerged regarding the optimal duration of denosumab treatment, the need for follow-on therapy upon denosumab discontinuation, and treatment sequencing or combination therapy with bone anabolic agents. This review addresses these questions using new insights gained over 10 years of clinical studies, including completion of the 7-year open-label extension of FREEDOM [10, 18, 19]. This article is based on previously conducted studies and does not contain any new studies with human participants or animals performed by any of the authors.

\section{DENOSUMAB EFFICACY}

\section{Denosumab Versus Bisphosphonates}

Denosumab prevents bone resorption through inhibition of the nuclear factor kappa-B (NF-кB) pathway by blocking binding of RANKL to RANK, which is expressed on the surface of osteoclast precursor cells and mature osteoclasts (Fig. 2) [20-23]. RANKL inhibition prevents differentiation of pre-osteoclasts and causes mature cells to undergo apoptosis [24]. Whereas bisphosphonates bind to the bone matrix, resulting in a slow resolution of their antiresorptive effect after discontinuation, the effects of denosumab, which is cleared from the circulation by the reticuloendothelial system, are rapidly reversible at the end of the 6-month dosing interval, at which time serum denosumab levels are very low [25-27]. The different MOAs translate into clinically meaningful differences in therapeutic efficacy and safety.

In two key publications, (1) the phase 3 Determining Efficacy: Comparison of Initiating Denosumab versus Alendronate (DECIDE) trial, in which treatment-naïve patients were randomized to alendronate or denosumab; and (2) a separate pooled analysis of four other studies, in which patients previously on a bisphosphonate were randomized to continue treatment with the same or a different bisphosphonate or switch to denosumab; denosumab increased BMD at 12 months to a greater degree than bisphosphonates at all skeletal sites assessed, and BTMs were lower in denosumab-treated subjects [28, 29]. These results showed that BMD increases more when a greater reduction of bone turnover is achieved, regardless of whether the initial rate of bone remodeling is high and imbalanced (resorption activity is greater than bone formation activity), as in naïve subjects, or low and balanced, as in previously bisphosphonate-treated subjects. It should be noted, however, that these studies had short follow-up times and small numbers of subjects, thus lacking statistical power to determine differences in fracture rates [29].

\section{FREEDOM Extension: Long-Term Efficacy Data}

The FREEDOM Extension enrolled 4550 subjects who completed the 3-year FREEDOM trial without missing more than one dose [18]. During the Extension, subjects in the former placebo arm received denosumab therapy for up to 7 years (crossover group), while the longterm group received denosumab therapy for up to 10 years (Fig. 1). Vertebral fracture incidence remained low and similar to than that observed in FREEDOM, whereas nonvertebral fracture rates further decreased with long-term treatment [10]. The most striking finding from the Extension was that denosumab produced continued and progressive increases in BMD, with mean BMD increments of $21.7 \%, 9.2 \%$, and 9.0\% for lumbar spine, total hip, and femoral neck, respectively, after 10 years of treatment [18]. In a post hoc analysis, improvements in BMD were associated with lower nonvertebral fracture rates beyond 3 years of therapy, a finding replicated in the crossover arm [30-32]. In contrast, with long-term bisphosphonates, BMD plateaus at the total hip after 3 years of therapy [33-35] (Fig. 3). These observations must be interpreted with caution, as attrition of the long-term cohort was observed over time, 


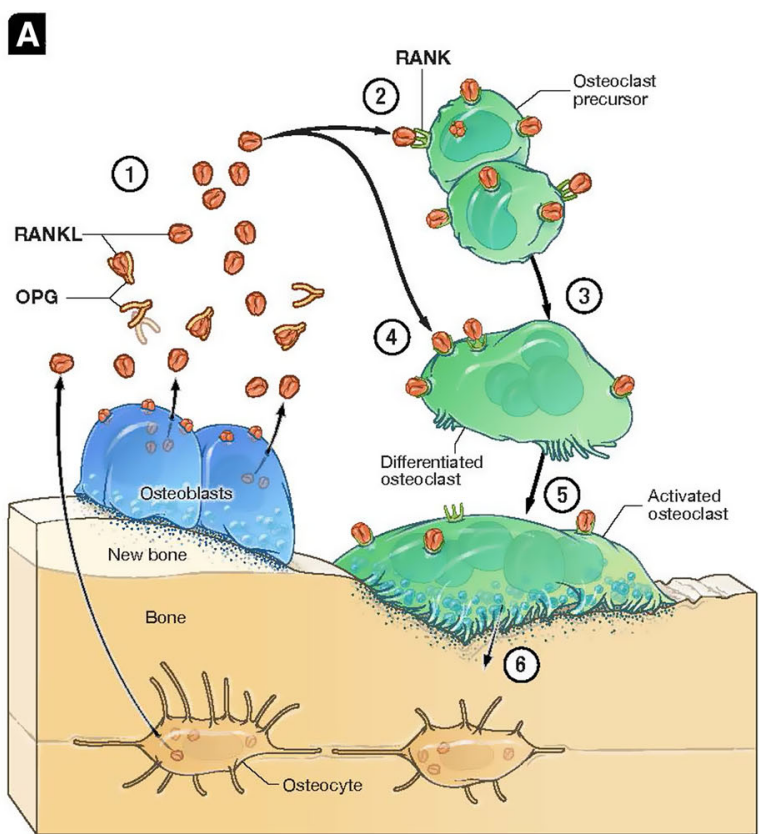

Fig. 2 Denosumab mechanism of action. A In response to pro-resorptive stimuli such as estrogen depletion after menopause, RANKL released from osteoblasts and osteocytes leads to osteoclast formation (2), (3) and activation (4), (5)). Osteoclast activation results in release of enzymes involved in the degradation of collagens and other proteins, cavity formation, and a decrease in bone mass (6) [20-22]. To physiologically suppress bone resorption, osteoclasts produce a soluble decoy protein called osteoprotegerin (OPG) that binds to and neutralizes RANKL

with loss of the oldest/frailest subjects; however, at completion of the Extension, the mean age was only 1 year younger than expected $[10,18,32,36]$.

\section{Effects of Denosumab on Bone Structure and Histology}

Post hoc analyses of FREEDOM revealed that denosumab progressively increased femoral and vertebral bone strength as assessed by finite element analysis 12,24 , and 36 months after initial treatment [37]. Bone biopsies from FREEDOM/FREEDOM Extension subjects taken at $2 / 3,5$, and 10 years showed denosumab treatment was associated with normal bone histology in the context of remodeling inhibition [38]. Bone matrix mineralization increased

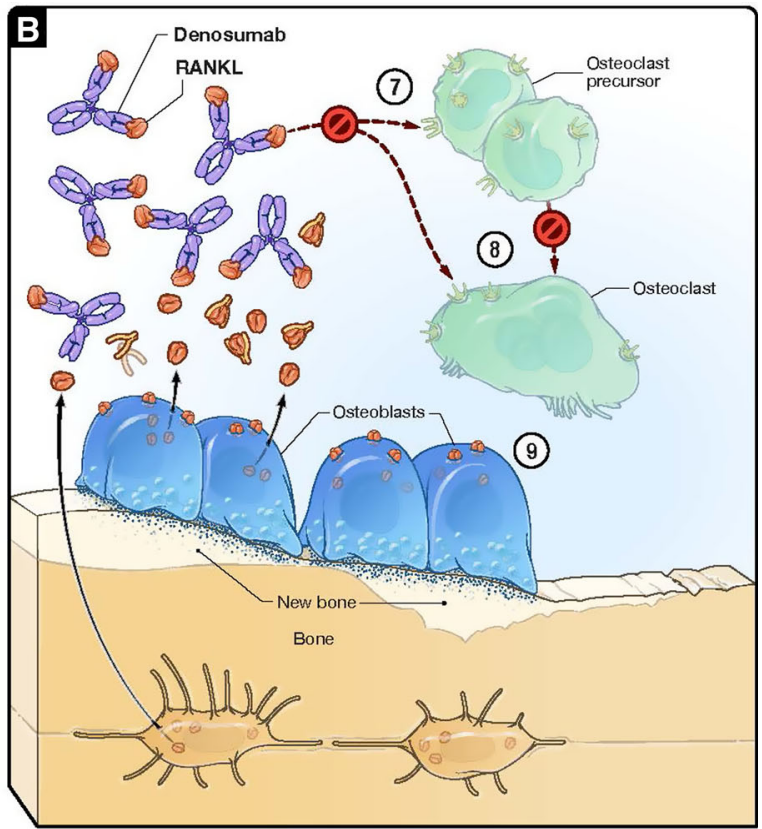

(1), thereby preventing RANKL from binding to RANK on precursor cells and mature osteoclasts [21]. B Denosumab acts in a manner similar to that of OPG and thus inhibits development of osteoclasts from precursor cells (7) as well as the function and survival of differentiated osteoclasts (8) $[23,24]$. This leads to a reduction in the release of protein-degrading enzymes, promotes refilling of resorption cavities by osteoblasts and leaves modelingbased bone formation unabated (9). Adapted from References [20] and [21]

with up to 5 years of denosumab treatment to nearly normal physiological levels and remained stable thereafter. Beyond 5 years, additional mechanisms may explain the continuous increases in BMD over 10 years of denosumab treatment [18, 39-42]. In the human femur, denosumab preserved the rate of modeling-based bone formation in the periosteum and endocortex, while also inhibiting remodeling-based formation [39]. Furthermore, in the iliac crest, erosion cavity depth was reduced in cortical remodeling units, while the size of newly formed bone packets was maintained, suggesting a positive bone balance within each remodeling unit [43]. Each of these processes might positively impact on bone microarchitecture, including increased cortical 


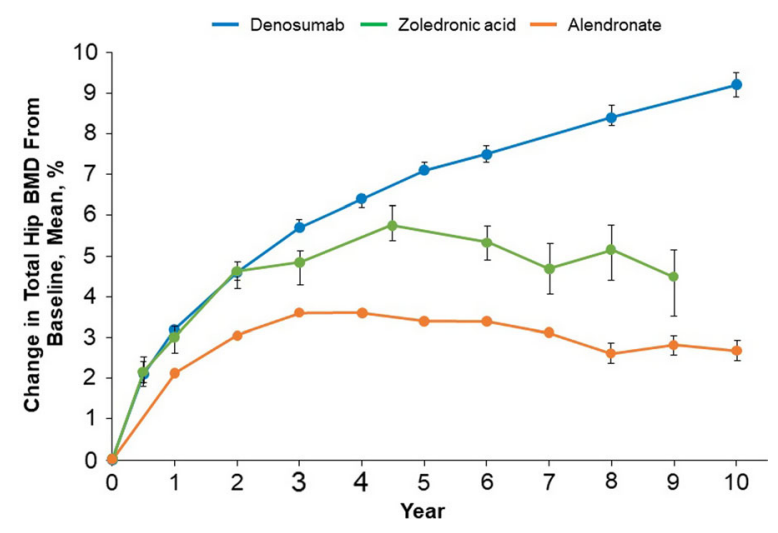

Fig. 3 Effects of antiresorptive osteoporosis treatments on hip BMD. Data derived from long-term follow-up studies of the FLEX trial (alendronate, 5-10 mg peroral per day), the HORIZON trial (zoledronic acid, $5 \mathrm{mg}$ intravenous infusion per year), and the FREEDOM trial (denosumab, $60 \mathrm{mg}$ subcutaneous injection every 6 months) $[18,33,34]$. As data are derived from separate studies, formal comparisons between changes in BMD have not been made. Error bars indicate $95 \%$ confidence intervals. Adapted from Reference [35]

thickness, bone density, and ultimately, bone strength [37, 44].

\section{SAFETY OF RANKL INHIBITION BY DENOSUMAB}

\section{FREEDOM Extension: Long-Term Safety Data}

The primary objective of the 7-year FREEDOM Extension was to describe the long-term safety profile of denosumab, particularly the effects of long-term suppression of bone turnover on bone quality and strength. As RANKL is also expressed on immune cells ( $\mathrm{T}$ and B cells), RANKL inhibition by denosumab could potentially affect immunity [45]. Hence, the Extension trial also investigated the incidence of infection and cancer in subjects treated with denosumab for up to 10 years.

No significant differences in AEs or serious AEs (SAEs) were observed between placebo- and denosumab-treated subjects in the original FREEDOM trial, with the exception of eczema and SAEs of cellulitis (including erysipelas), which were more frequent in denosumabtreated subjects (12 subjects developed cellulitis on denosumab versus 1 on placebo) [10]. In the aging study population, the subject incidence of AEs such as infection, cellulitis, and malignancy remained low in the Extension [18]. No subjects developed neutralizing antibodies to denosumab. These results support the conclusion that RANKL inhibition by denosumab is generally safe and well tolerated for up to 10 years of use.

No ONJ or AFF cases were observed during FREEDOM [10]. Two AFFs were adjudicated in the Extension, with a calculated incidence of 0.8 AFFs per 10,000 subject-years, and there was no clear association between length of treatment and risk of AFF [18]. Only 13 adjudicated cases of ONJ (defined as delayed dental healing with persistence of exposed bone after 8 weeks of conservative therapy) occurred during the Extension (5.2 per 10,000 subject-years), of which 9 had an inciting event such as tooth extraction or denture involvement [46]. Of the ONJ lesions that developed, 11/13 were assessed as mild or moderate. In 7 of 8 subjects who received denosumab after $\mathrm{ONJ}$ onset, the lesions resolved on therapy, and in the remaining subject, the lesion was ongoing at end of study.

Because there was no placebo group in the FREEDOM Extension, the virtual-twin method was used to calculate the fractures prevented in the long-term denosumab group (versus the virtual placebo group). The calculated fracture risk reduction was compared to the number of AFF or ONJ events observed in the long-term group [47]. This skeletal benefit/risk ratio (clinical fractures prevented per skeletal $\mathrm{AE}$ observed) was 281 for AFF and 40 for ONJ. Among subjects in FREEDOM/FREEDOM Extension who experienced an on-study fracture while taking denosumab, risk of a subsequent osteoporotic fracture was still significantly lower than for subjects who experienced another fracture while taking placebo [48]. 


\section{Risk of Multiple Vertebral Fractures After Discontinuation}

Several clinical trials have demonstrated the reversibility of denosumab-mediated effects on bone. In a phase 2 dose-ranging study of subjects treated with denosumab for 24 months, discontinuing therapy resulted in a decrease in BMD within 12 months that was comparable to the increase in BMD after 24 months on treatment [27]. Similar results were seen in a phase 3 study in which subjects treated with denosumab for 24 months were followed for 24 months after discontinuation, with BMD returning to baseline within 1 year [25]. A rebound increase in BTMs above pretreatment levels was observed, with C-terminal telopeptide of type 1 collagen (CTx) being maximally increased 12 months after the last denosumab injection. Bone biopsies taken 21-29 months after denosumab discontinuation in a small number of subjects treated for 1 year showed similar histology and levels of bone remodeling to those from placebo-treated subjects, confirming that the effects of denosumab on bone turnover are fully reversible [49]. It is not yet clear whether bone turnover rebound is proportional to duration of denosumab therapy; however, there is evidence that pre- and postdenosumab bone turnover levels are closely related [49].

The clinical consequence of the rapid rebound in bone turnover after denosumab discontinuation is increased risk of multiple vertebral fractures (MVF) [50, 51]. In many cases, affected individuals have other risk factors for fracture such as prior vertebral fracture, low spine BMD, glucocorticoid use, or aromatase inhibitor therapy and would not be recommended for treatment discontinuation [51].

In subjects who discontinued denosumab but remained in the FREEDOM and Extension studies, overall fracture rates rose to levels similar to those in untreated subjects $(7 \%$ for FREEDOM subjects who discontinued denosumab versus $9 \%$ in the placebo group) $[19,52]$. The MVF rate per 100 subject-years after discontinuation was 3.2 for placebo-treated subjects and 4.2 for denosumab-treated subjects, with 13 of 1471 subjects who discontinued denosumab having four or more vertebral fractures (compared with only two in the FREEDOM placebo group). Subjects with prior vertebral fractures sustained before or during treatment had a 3.9-fold higher risk of developing MVFs; however, as follow-up time in FREEDOM and its Extension was relatively short, data are insufficient to estimate the real-world risk of fracture after therapy is stopped.

\section{DENOSUMAB IN CLINICAL PRACTICE}

\section{When to Choose Denosumab}

Questions remain in the treatment community regarding optimal use of denosumab, including its suitability for goal-directed therapy, appropriate strategies for discontinuation, and use in treatment sequencing or combination therapy with anabolic agents. Here, we discuss what has been learned about use of denosumab in the clinic and how this therapy fits within the armamentarium of the practitioner.

\section{Denosumab in Goal-Directed Therapy}

The demonstration of progressive BMD gains with long-term denosumab has contributed to the exploration of goal-directed therapy in osteoporosis, also called a treat-to-target approach, where one or more metrics are used to determine the level of response at which it is safe or advantageous to change or discontinue therapy [19]. Integral in the goal-directed therapy concept is use of a clinically meaningful goal, such as absence of fracture. Because this particular goal is difficult to measure in the clinic, a meaningful surrogate target must be used, such as increase in bone mass; thus, BMD $T$-score has been proposed as an appropriate therapeutic target for osteoporosis [31]. Although other methods have been used to assess fracture risk, a strong correlation has been demonstrated between change in BMD and fracture risk reduction [53]. Analysis of FREEDOM Extension data showed a clear 
relationship between total hip $T$-scores achieved while on denosumab treatment at any time point and subsequent risk of nonvertebral and vertebral fractures [31]. These effects appeared to plateau when a hip $T$-score of approximately -1.5 was attained on treatment (Fig. 4). Therefore, some patients might benefit from continuing denosumab to achieve a target BMD up to that level, rather than the minimal target $T$-score above -2.5 .

Osteoporosis is a chronic condition that generally requires long-term monitoring and therapy. Even though the maximum follow-up time for published clinical data on the longterm effects of denosumab treatment is 10 years, there is no absolute limit on treatment duration [31]. In some patients at continued high risk for fracture, treatment with denosumab should be continued indefinitely.

Given the high individual variability in starting BMD as well as variable BMD treatment targets, the treatment duration required to achieve treatment goals is highly variable. Other factors, including patient age, bisphosphonate tolerance, underlying comorbidities, and fall risk, will also play a role. For these reasons, the decision to continue denosumab

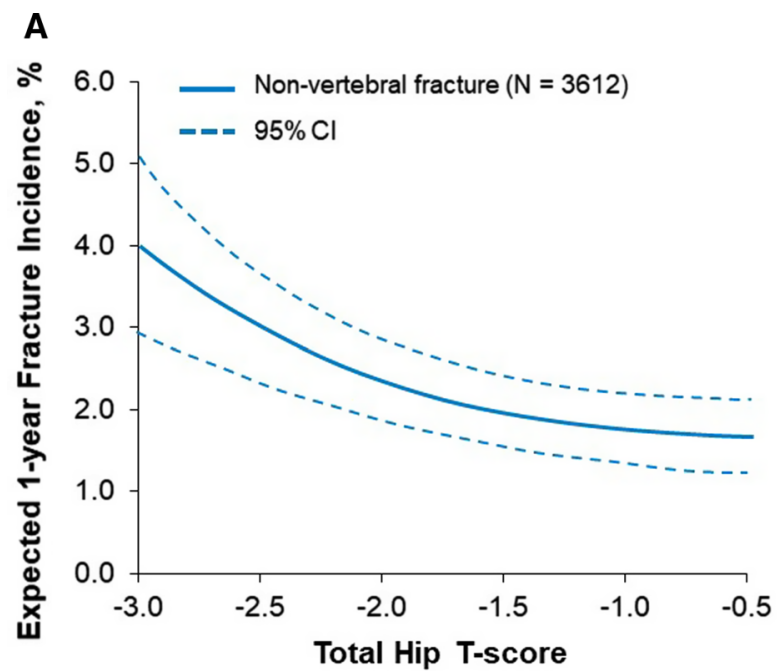

Fig. 4 Relationship between BMD $T$-score and fracture risk. An analysis of FREEDOM Extension data showed a clear relationship between hip BMD $T$-scores achieved in response to denosumab treatment and subsequent 1-year treatment must be individualized; thus, there can be no single recommended optimal treatment duration.

\section{Discontinuation of Denosumab}

Denosumab discontinuation might be considered in several clinical circumstances: (1) patient remains fracture-free and has achieved low fracture risk; (2) patient has suboptimal response to denosumab with incident fracture, declining BMD, or persistently low BMD; or (3) patient develops hypersensitivity or other adverse effects to denosumab such as ONJ or AFF. In some cases, patients may request to discontinue denosumab for cost or other reasons.

Administration of a bisphosphonate after denosumab discontinuation has been proposed as a strategy for preventing BMD loss and maintaining a reduced risk of fracture [54]. Follow-on treatment with alendronate or zoledronic acid maintained some of the therapeutic benefits of denosumab on BMD, with a low incidence of fracture, while follow-on therapy with zoledronic acid 6 months after the last denosumab dose in subjects treated an average

\section{B}

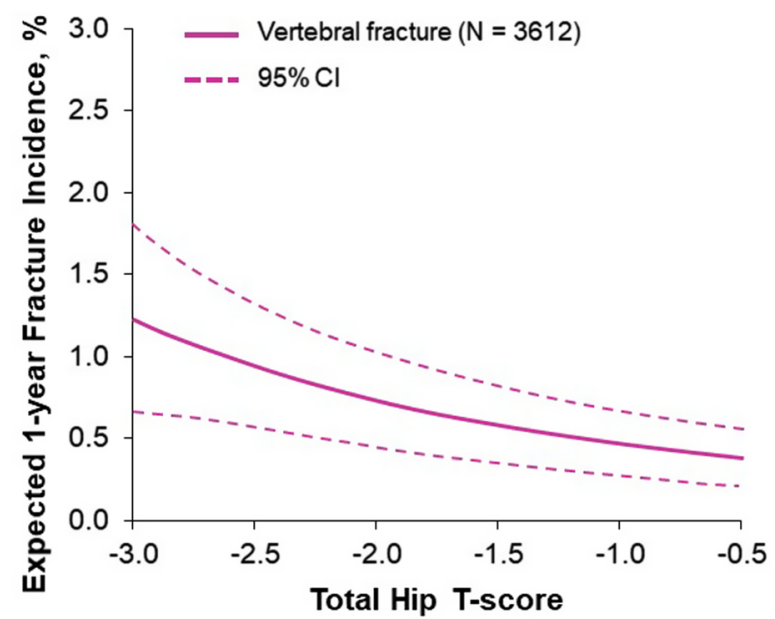

incidence of $\mathbf{A}$ nonvertebral or $\mathbf{B}$ vertebral fractures. Achievement of hip BMD $T$-scores $>-1.5$ did not further reduce the nonvertebral fracture incidence. Adapted from Reference [31] 
of 2.2 years resulted in only small increases in BTMs [55-59]. However, in a trial including subjects with longer average exposure to denosumab (4.6 years) who were randomized to receive zoledronic acid either 6 or 9 months after the last dose of denosumab, or upon an increase in bone turnover (average 10.4 months after last dose of denosumab), similar BMD loss (on average $5 \%$ at 12 months) and increases in BTMs were seen at 6 and 12 months in all treatment groups [60]. These decreases in BMD represent only a portion of the BMD increases usually seen with long-term denosumab therapy, perhaps suggesting clinicians target a higher BMD before discontinuing denosumab. Ongoing clinical studies are exploring various approaches for mitigating the effects of denosumab discontinuation (Table 1).

A challenge regarding stopping denosumab occurs in patients who are not candidates for bisphosphonates, such as those who have renal insufficiency, sustained AFFs, or recalcitrant ONJ. Pro-remodeling agents (teriparatide, abaloparatide) may be a therapeutic option for some of these patients $[61,62]$ but duration of therapy is limited. For those with newly diagnosed ONJ, stopping denosumab temporarily or permanently is not usually recommended because the risk of rapid bone loss and MVF far outweighs any potential additional negative impact of denosumab on the clinical course of ONJ. Treatment with local antiseptic rinses and/ or systemic antibiotics might reduce the risk of ONJ in patients on antiresorptive therapy who require oral surgical procedures such as extraction or dental implantation [63]. For patients with AFF, it is not clear whether denosumab can be administered safely; several cases have been described with recurrent AFF after treatment with denosumab [61, 64].

\section{Use of Denosumab in Treatment Sequencing and Combination Therapy}

Strategies that employ anabolic agents first, followed by potent antiresorptive therapies, are highly effective at reducing fracture risk rapidly and producing large BMD gains. In the FRAME study, subjects receiving bone-forming agent romosozumab for 12 months followed by 12 months of denosumab had a sustained reduction in fracture risk and further increase in BMD across the 24-month treatment sequence [65] and after an additional year of denosumab in the FRAME study Extension [66].

The combination of denosumab and teriparatide was compared with either agent alone in the 2-year DATA trial in a small number of women $(n=94)$. In the combination group, BMD gains were larger at both spine and hip during the first year of treatment than with either agent alone, but this advantage was not seen during the second year $[67,68]$. In the DATA-Switch study, subjects randomized to receive the bone-forming agent teriparatide for 24 months and then switched to denosumab for 24 months experienced substantial increases in BMD [69]. In contrast, those randomized to receive denosumab as initial therapy for 24 months and then switched to teriparatide for 24 months experienced progressive or transient bone loss at the hip during teriparatide therapy, though spine BMD increased. For patients who remain at high risk of fracture despite denosumab treatment, another option is to add teriparatide or abaloparatide and continue denosumab; however, this approach has not yet been tested.

Cyclical administration of 6 months of teriparatide followed by 6 months of denosumab for 36 months (3 cycles) versus 18 months of teriparatide followed by 18 months of denosumab produced hip and radius BMD benefits at 18 months but no significant differences at 36 months [70]. A comparison of subjects who transitioned from bisphosphonate to denosumab or teriparatide showed that hip BMD increased with denosumab over 2 years but was unchanged with teriparatide; anti-fracture efficacy data are not available [71]. In a small study, transition from denosumab to romosozumab resulted in spine BMD gain and hip BMD stability [72]. The anti-fracture efficacy of these novel regimens has not been determined and is a major limitation. 
Table 1 Studies to inform treatment strategies in osteoporosis after denosumab discontinuation

\begin{tabular}{|c|c|c|c|c|}
\hline Study & $\begin{array}{l}\text { Post- } \\
\text { discontinuation } \\
\text { agent }\end{array}$ & Investigator & Status & Trial identifier \\
\hline $\begin{array}{l}\text { Importance of prompt antiresorptive therapy in } \\
\text { postmenopausal women discontinuing } \\
\text { teriparatide or denosumab: the Denosumab and } \\
\text { Teriparatide Follow-up study (DATA-Follow- } \\
\text { up) [78] }\end{array}$ & $\begin{array}{l}\text { Oral } \\
\text { bisphosphonates } \\
\text { Zoledronic acid }\end{array}$ & $\begin{array}{l}\text { Leder } \\
\text { Massachusetts } \\
\text { General } \\
\text { Hosp, USA }\end{array}$ & $\begin{array}{l}\text { Completed/ } \\
\text { Published }\end{array}$ & NCT00926380 \\
\hline $\begin{array}{l}\text { Effects of follow-on therapy after denosumab } \\
\text { discontinuation in patients with } \\
\text { postmenopausal osteoporosis [79] }\end{array}$ & $\begin{array}{l}\text { Raloxifene } \\
\text { Zoledronic acid }\end{array}$ & $\begin{array}{l}\text { Ebina } \\
\text { Osaka } \\
\text { University, } \\
\text { Japan }\end{array}$ & $\begin{array}{l}\text { Completed/ } \\
\text { Published }\end{array}$ & $\mathrm{N} / \mathrm{A}$ \\
\hline $\begin{array}{l}\text { Zoledronic acid to maintain bone mass after } \\
\text { denosumab discontinuation (AfterDmab) [80] }\end{array}$ & Zoledronic acid & $\begin{array}{l}\text { Anastasilakis } \\
\text { Gen Military } \\
\text { Hosp, Greece }\end{array}$ & $\begin{array}{l}\text { Completed/ } \\
\text { Published }\end{array}$ & NCT02499237 \\
\hline $\begin{array}{l}\text { A single infusion of zoledronate in } \\
\text { postmenopausal women following denosumab } \\
\text { discontinuation results in partial conservation } \\
\text { of bone mass gains [57] }\end{array}$ & Zoledronic acid & $\begin{array}{l}\text { Everts-Graber } \\
\text { OsteoRheuma } \\
\text { Bern, } \\
\text { Switzerland }\end{array}$ & $\begin{array}{l}\text { Completed/ } \\
\text { Published }\end{array}$ & $\mathrm{N} / \mathrm{A}$ \\
\hline $\begin{array}{l}\text { Zoledronic acid sequential therapy could avoid } \\
\text { disadvantages due to the discontinuation of less } \\
\text { than 3-year denosumab treatment }[81]\end{array}$ & Zoledronic acid & $\begin{array}{l}\text { Kondo } \\
\text { Fukuoka, Japan }\end{array}$ & $\begin{array}{l}\text { Completed/ } \\
\text { Published }\end{array}$ & $\mathrm{N} / \mathrm{A}$ \\
\hline $\begin{array}{l}\text { Treatment with zoledronic acid subsequent to } \\
\text { denosumab in osteoporosis (ZOLARMAB) } \\
{[60]}\end{array}$ & Zoledronic acid & $\begin{array}{l}\text { Langdahl } \\
\text { Univ Aarhus, } \\
\text { Denmark }\end{array}$ & $\begin{array}{l}\text { Ongoing } \\
\text { through } \\
\text { December } \\
2021 \\
\text { Interim } \\
\text { results } \\
\text { published }\end{array}$ & NCT03087851 \\
\hline $\begin{array}{l}\text { Treatment with zoledronic acid subsequent to } \\
\text { denosumab in osteoporosis (ZOLARMAB- } \\
\text { Switzerland) (Ferrari S. Personal } \\
\text { communication) }\end{array}$ & Zoledronic acid & $\begin{array}{l}\text { Ferrari } \\
\text { Geneva } \\
\text { University } \\
\text { Hosp, } \\
\text { Switzerland }\end{array}$ & Ongoing & N/A \\
\hline $\begin{array}{l}\text { Comparative antiresorptive efficacy } \\
\text { discontinuation of denosumab [82] }\end{array}$ & $\begin{array}{l}\text { Alendronate } \\
\text { Raloxifene }\end{array}$ & $\begin{array}{l}\text { Tsai } \\
\text { Massachusetts } \\
\text { General } \\
\text { Hosp, USA }\end{array}$ & $\begin{array}{l}\text { Ongoing } \\
\text { through } \\
\text { December } \\
2021\end{array}$ & NCT03623633 \\
\hline
\end{tabular}


Table 1 continued

\begin{tabular}{|c|c|c|c|c|}
\hline$\overline{\text { Study }}$ & $\begin{array}{l}\text { Post- } \\
\text { discontinuation } \\
\text { agent }\end{array}$ & Investigator & Status & Trial identifier \\
\hline $\begin{array}{l}\text { Alendronate in an weekly effervescent tablet } \\
\text { formulation following denosumab } \\
\text { discontinuation (BAD) [83] }\end{array}$ & Alendronate & $\begin{array}{l}\text { Anastasilakis } \\
\text { Gen Military } \\
\text { Hosp, Greece }\end{array}$ & $\begin{array}{l}\text { Ongoing } \\
\text { through } \\
\text { April } 2022\end{array}$ & NCT04338529 \\
\hline Denosumab sequential therapy (DST) [84] & Zoledronic acid & $\begin{array}{l}\text { Fu/Lee } \\
\text { National } \\
\text { Taiwan } \\
\text { University } \\
\text { Hospital }\end{array}$ & $\begin{array}{l}\text { Ongoing } \\
\text { through } \\
\text { December } \\
2022\end{array}$ & NCT03868033 \\
\hline $\begin{array}{l}\text { Bisphosphonates for prevention of post- } \\
\text { denosumab bone loss [85] }\end{array}$ & $\begin{array}{l}\text { Zoledronic acid } \\
\text { Alendronate }\end{array}$ & $\begin{array}{l}\text { Shane } \\
\text { Columbia } \\
\text { University, } \\
\text { USA }\end{array}$ & $\begin{array}{l}\text { Ongoing } \\
\text { through } \\
\text { January } \\
2023\end{array}$ & NCT03396315 \\
\hline $\begin{array}{l}\text { Preventing osteoporosis using denosumab } \\
\text { (PROUD) [86] }\end{array}$ & Zoledronic acid & $\begin{array}{l}\text { Greenspan } \\
\text { NIH, USA }\end{array}$ & $\begin{array}{l}\text { Ongoing } \\
\text { through } \\
\text { September } \\
2023\end{array}$ & NCT02753283 \\
\hline $\begin{array}{l}\text { Examination of efficacy and safety of other anti- } \\
\text { resorption drugs after 2-year-denosumab } \\
\text { therapy in Japanese osteoporosis patients } \\
\text { [87] }\end{array}$ & $\begin{array}{l}\text { SERM and } \\
\text { eldecalcitol } \\
\text { Bisphosphonate } \\
\text { and eldecalcitol } \\
\text { Eldecalcitol alone }\end{array}$ & $\begin{array}{l}\text { Nakamura } \\
\text { Shinshu } \\
\text { University, } \\
\text { Japan }\end{array}$ & $\begin{array}{l}\text { Ongoing } \\
\text { through } \\
\text { November } \\
2025\end{array}$ & NCT03755193 \\
\hline
\end{tabular}

\section{CONCLUSION}

Ten years after approval of denosumab, many initial questions regarding its use have been answered through the FREEDOM Extension and additional studies:

- Long-term suppression of bone turnover by denosumab results in a positive bone mineral balance in both trabecular and cortical bone, leading to continuous BMD gains and a sustained reduction of fracture with very few cases of AFF and ONJ.

- No increases in infection or cancer rates were observed, indicating no impairment of immunological functions during long-term RANKL inhibition.

- The reversibility of denosumab leads to BMD loss upon discontinuation and an increased risk of MVFs, particularly in high-risk patients. Transition to bisphosphonates (a different class of antiresorptive) upon denosumab discontinuation will mitigate or completely prevent this loss and is therefore recommended.

The primary efficacy benefit of denosumab compared with bisphosphonates is the larger, continuous BMD increase for at least 10 years, and growing evidence suggests denosumab may be appropriate as initial anti-osteoporosis 
therapy in patients at high or very high risk of fracture [73-75].

The optimal duration of denosumab treatment should be guided by clinical judgment and regular re-evaluation of fracture risk, including BMD. There is a need for follow-on therapy upon denosumab interruption, with transition to bisphosphonate treatment likely to be recommended for many patients. For patients who discontinue denosumab and experience rapid bone loss despite bisphosphonate administration, retreatment with denosumab is likely to restore BMD. In patients who are not candidates for bisphosphonate therapy or who remain at high risk of fracture despite denosumab treatment, continuing denosumab is an option.

There is potential value for denosumab in treatment sequencing and, possibly, combination therapy with bone-forming agents. Transition from denosumab to an anabolic agent or continuing denosumab and adding an anabolic agent may be desirable for some very high-risk individuals. For very high-risk patients who are able to receive anabolic therapy as initial treatment, subsequent transition to denosumab will provide greater BMD increments than transition to bisphosphonates $[65,76,77]$.

Over the last 10 years, denosumab has become a well-established treatment option in the armamentarium of both primary care and specialist practitioners. Osteoporosis is a chronic health disorder requiring a long-term treatment strategy, and denosumab has a unique utility/versatility for protecting highrisk patients from the long-term health impact of osteoporotic fractures. Further research is required to assess the effects of long-term denosumab therapy on bone formation, use of denosumab in patients with comorbidities such as diabetes, and impact of denosumab on muscle and other non-bone tissues.

\section{ACKNOWLEDGEMENTS}

Funding. This review and Rapid Service Fee were funded by Amgen Inc.
Medical Writing and Editorial Assistance. Kate Smigiel, PhD, of Amgen Inc. provided medical writing support, and Amy Volpert of BioScience Communications, New York, NY (on behalf of Amgen Inc.) provided medical writing and editorial support.

Authorship. All named authors meet the International Committee of Medical Journal Editors (ICMJE) criteria for authorship for this article, take responsibility for the integrity of the work as a whole, and have given their approval for this version to be published.

Author Contributions. Conceptualization: David L. Kendler, Felicia Cosman, Robert Kees Stad, Serge Ferrari (equal); Writing-review and editing: David L. Kendler, Felicia Cosman, Robert Kees Stad, Serge Ferrari (equal).

Disclosures. David L. Kendler reports consultancies: Amgen, Eli Lilly, Pfizer; honoraria for advice or public speaking: Amgen, Eli Lilly; grants/research support: Radius, AstraZeneca. Felicia Cosman reports consultancies: Amgen, Eli Lilly, Radius, Obseva, Enterabio; honoraria for advice or public speaking: Amgen, Eli Lilly, Radius; grants/research support: Amgen, Eli Lilly, Radius. Robert Kees Stad is an employee and stockholder of Amgen. Serge Ferrari reports consultancies: Amgen, UCB, Agnovos, Radius Health, Gedeon Richter, Galapagos Health; grants/research support: Amgen, UCB, Agnovos, Alexion.

Compliance with Ethics Guidelines. This article is based on previously conducted studies and does not contain any new studies with human participants or animals performed by any of the authors.

Data Availability. Qualified researchers may request data from Amgen clinical studies. Complete details are available at the following: https://wwwext.amgen.com/science/clinicaltrials/clinical-data-transparency-practices/ clinical-trial-data-sharing-request/.

Open Access. This article is licensed under a Creative Commons Attribution- 
NonCommercial 4.0 International License, which permits any non-commercial use, sharing, adaptation, distribution and reproduction in any medium or format, as long as you give appropriate credit to the original author(s) and the source, provide a link to the Creative Commons licence, and indicate if changes were made. The images or other third party material in this article are included in the article's Creative Commons licence, unless indicated otherwise in a credit line to the material. If material is not included in the article's Creative Commons licence and your intended use is not permitted by statutory regulation or exceeds the permitted use, you will need to obtain permission directly from the copyright holder. To view a copy of this licence, visit http:// creativecommons.org/licenses/by-nc/4.0/.

\section{REFERENCES}

1. Cosman F. Long-term treatment strategies for postmenopausal osteoporosis. Curr Opin Rheumatol. 2018;30:420-6.

2. Khosla S, Cauley JA, Compston J, et al. Addressing the crisis in the treatment of osteoporosis: a path forward. J Bone Miner Res. 2017;32:424-30.

3. Langdahl BL, Andersen JD. Treatment of osteoporosis: unmet needs and emerging solutions. J Bone Metab. 2018;25:133-40.

4. Simonet WS, Lacey DL, Dunstan CR, et al. Osteoprotegerin: a novel secreted protein involved in the regulation of bone density. Cell. 1997;89:309-19.

5. Kostenuik PJ. Osteoprotegerin and RANKL regulate bone resorption, density, geometry and strength. Curr Opin Pharmacol. 2005;5:618-25.

6. Prolia $^{\circledR}$ (denosumab) [prescribing Information]. Thousand Oaks: Amgen; 2019. https://www.pi. amgen.com/ /media/amgen/repositorysites/piamgen-com/prolia/prolia_pi.ashx. Accessed 2 Apr 2021.

7. European Medicines Agency. Prolia (denosumab). Summary for the Public. https://www.ema.europa. eu/en/documents/overview/prolia-epar-summarypublic_en.pdf. Accessed 2 Apr 2021.
8. Lewiecki EM. Clinical use of denosumab for the treatment for postmenopausal osteoporosis. Curr Med Res Opin. 2010;26:2807-12.

9. Tsourdi E, Ominsky MS, Rachner TD, Hofbauer LC, Kostenuik PJ. Pharmacological mechanisms of therapeutics: receptor activator of nuclear factor-kappa B ligand inhibition. In: Bilezikian JP, Martin TJ, Clemens TL, Rosen CJ, editors. Principles of bone biology. 4th ed. Academic; 2020. p. 1689-710.

10. Cummings SR, San Martin J, McClung MR, et al. Denosumab for prevention of fractures in postmenopausal women with osteoporosis. N Engl J Med. 2009;361:756-65.

11. Simon JA, Recknor C, Moffett AH, et al. Impact of denosumab on the peripheral skeleton of postmenopausal women with osteoporosis: bone density, mass, and strength of the radius, and wrist fracture. Menopause. 2013;20:130-7.

12. Eastell R, Christiansen C, Grauer A, et al. Effects of denosumab on bone turnover markers in postmenopausal osteoporosis. J Bone Miner Res. 2011;26:530-7.

13. Austin M, Yang Y-C, Vittinghoff E, et al. Relationship between bone mineral density changes with denosumab treatment and risk reduction for vertebral and nonvertebral fractures. J Bone Miner Res. 2012;27:687-93.

14. Adami S, Libanati C, Boonen S, et al. Denosumab treatment in postmenopausal women with osteoporosis does not interfere with fracture-healing: results from the FREEDOM trial. J Bone Jt Surg Am. 2012;94:2113-9.

15. Block GA, Bone HG, Fang L, Lee E, Padhi D. A single-dose study of denosumab in patients with various degrees of renal impairment. J Bone Miner Res. 2012;27:1471-9.

16. Jamal SA, Ljunggren O, Stehman-Breen $C$, et al. Effects of denosumab on fracture and bone mineral density by level of kidney function. J Bone Miner Res. 2011;26:1829-35.

17. Broadwell A, Chines A, Ebeling PR, et al. Denosumab safety and efficacy among participants in the FREEDOM Extension study with mild-to-moderate chronic kidney disease. J Clin Endocrinol Metab. 2021;106:397-409.

18. Bone HG, Wagman RB, Brandi ML, et al. 10 years of denosumab treatment in postmenopausal women with osteoporosis: results from the phase 3 randomised FREEDOM trial and open-label extension. Lancet Diabetes Endocrinol. 2017;5:513-23. 
19. Cummings SR, Ferrari S, Eastell R, et al. Vertebral fractures after discontinuation of denosumab: a post hoc analysis of the randomized placebo-controlled FREEDOM trial and its extension. J Bone Miner Res. 2018;33:190-8.

20. Boyle WJ, Simonet WS, Lacey DL. Osteoclast differentiation and activation. Nature. 2003;423: 337-42.

21. Delmas PD. Clinical potential of RANKL inhibition for the management of postmenopausal osteoporosis and other metabolic bone diseases. J Clin Densitom. 2008;11:325-38.

22. Nakashima T, Hayashi M, Fukunaga T, et al. Evidence for osteocyte regulation of bone homeostasis through RANKL expression. Nat Med. 2011;17: 1231-4.

23. Ikebuchi $\mathrm{Y}$, Aoki S, Honma M, et al. Coupling of bone resorption and formation by RANKL reverse signalling. Nature. 2018;561:195-200.

24. Baron R, Ferrari S, Russell RGG. Denosumab and bisphosphonates: different mechanisms of action and effects. Bone. 2011;48:677-92.

25. Bone HG, Bolognese MA, Yuen CK, et al. Effects of denosumab treatment and discontinuation on bone mineral density and bone turnover markers in postmenopausal women with low bone mass. J Clin Endocrinol Metab. 2011;96:972-80.

26. Kim TY, Bauer DC, McNabb BL, et al. Comparison of BMD changes and bone formation marker levels 3 years after bisphosphonate discontinuation: FLEX and HORIZON-PFT Extension I trials. J Bone Miner Res. 2019;34:810-6.

27. Miller PD, Bolognese MA, Lewiecki EM, et al. Effect of denosumab on bone density and turnover in postmenopausal women with low bone mass after long-term continued, discontinued, and restarting of therapy: a randomized blinded phase 2 clinical trial. Bone. 2008;43:222-9.

28. Brown JP, Prince RL, Deal C, et al. Comparison of the effect of denosumab and alendronate on BMD and biochemical markers of bone turnover in postmenopausal women with low bone mass: a randomized, blinded, phase 3 trial. J Bone Miner Res. 2009;24:153-61.

29. Miller PD, Pannacciulli N, Malouf-Sierra J, et al. Efficacy and safety of denosumab vs. bisphosphonates in postmenopausal women previously treated with oral bisphosphonates. Osteoporos Int. 2020;31:181-91.

30. Ferrari S, Butler PW, Kendler DL, et al. Further nonvertebral fracture reduction beyond 3 years for up to 10 years of denosumab treatment. J Clin Endocrinol Metab. 2019;104:3450-61.

31. Ferrari S, Libanati C, Lin CJF, et al. Relationship between bone mineral density T-score and nonvertebral fracture risk over 10 years of denosumab treatment. J Bone Miner Res. 2019;34:1033-40.

32. Bilezikian JP, Lin CJF, Brown JP, et al. Long-term denosumab treatment restores cortical bone loss and reduces fracture risk at the forearm and humerus: analyses from the FREEDOM Extension cross-over group. Osteoporos Int. 2019;30:1855-64.

33. Black DM, Schwartz AV, Ensrud KE, et al. Effects of continuing or stopping alendronate after 5 years of treatment: the Fracture Intervention Trial Longterm Extension (FLEX): a randomized trial. JAMA. 2006;296:2927-38.

34. Black DM, Reid IR, Boonen S, et al. The effect of 3 versus 6 years of zoledronic acid treatment of osteoporosis: a randomized extension to the HORIZON-Pivotal Fracture Trial (PFT). J Bone Miner Res. 2012;27:243-54.

35. Reid IR. Short-term and long-term effects of osteoporosis therapies. Nat Rev Endocrinol. 2015;11: 418-28.

36. Adachi JD, Bone HG, Daizadeh NS, et al. Influence of subject discontinuation on long-term nonvertebral fracture rate in the denosumab FREEDOM Extension study. BMC Musculoskelet Disord. 2017;18:174.

37. Keaveny TM, McClung MR, Genant HK, et al. Femoral and vertebral strength improvements in postmenopausal women with osteoporosis treated with denosumab. J Bone Miner Res. 2014;29: 158-65.

38. Dempster DW, Brown JP, Fahrleitner-Pammer A, et al. Effects of long-term denosumab on bone histomorphometry and mineralization in women with postmenopausal osteoporosis. J Clin Endocrinol Metab. 2018;103:2498-509.

39. Dempster DW, Chines A, Bostrom MP, et al. Modeling-based bone formation in the human femoral neck in subjects treated with denosumab. J Bone Miner Res. 2020;35:1282-8.

40. Dempster DW, Zhou H, Recker RR, et al. Remodeling- and modeling-based bone formation with teriparatide versus denosumab: a longitudinal analysis from baseline to 3 months in the AVA study. J Bone Miner Res. 2018;33:298-306.

41. Langdahl B, Ferrari S, Dempster DW. Bone modeling and remodeling: potential as therapeutic targets 
for the treatment of osteoporosis. Ther Adv Musculoskelet Dis. 2016;8:225-35.

42. Reid IR, Miller PD, Brown JP, et al. Effects of denosumab on bone histomorphometry: the FREEDOM and STAND studies. J Bone Miner Res. 2010;25: 2256-65.

43. Chavassieux P, Portero-Muzy N, Roux JP, et al. Reduction of cortical bone turnover and erosion depth after 2 and 3 years of denosumab: iliac bone histomorphometry in the FREEDOM trial. J Bone Miner Res. 2019;34:626-31.

44. McClung MR, Lippuner K, Brandi ML, et al. Effect of denosumab on trabecular bone score in postmenopausal women with osteoporosis. Osteoporos Int. 2017;28:2967-73.

45. Ferrari-Lacraz S, Ferrari S. Do RANKL inhibitors (denosumab) affect inflammation and immunity? Osteoporos Int. 2011;22:435-46.

46. Watts NB, Grbic JT, Binkley N, et al. Invasive oral procedures and events in postmenopausal women with osteoporosis treated with denosumab for up to 10 years. J Clin Endocrinol Metab. 2019;104: 2443-52.

47. Ferrari S, Lewiecki EM, Butler PW, et al. Favorable skeletal benefit/risk of long-term denosumab therapy: a virtual-twin analysis of fractures prevented relative to skeletal safety events observed. Bone. 2020;134:115287.

48. Kendler DL, Chines A, Brandi ML, et al. The risk of subsequent osteoporotic fractures is decreased in subjects experiencing fracture while on denosumab: results from the FREEDOM and FREEDOM Extension studies. Osteoporos Int. 2019;30:71-8.

49. Brown JP, Dempster DW, Ding B, et al. Bone remodeling in postmenopausal women who discontinued denosumab treatment: off-treatment biopsy study. J Bone Miner Res. 2011;26:2737-44.

50. Aubry-Rozier B, Gonzalez-Rodriguez E, Stoll D, Lamy O. Severe spontaneous vertebral fractures after denosumab discontinuation: three case reports. Osteoporos Int. 2016;27:1923-5.

51. Lamy O, Gonzalez-Rodriguez E, Stoll D, Hans D, Aubry-Rozier B. Severe rebound-associated vertebral fractures after denosumab discontinuation: 9 clinical cases report. J Clin Endocrinol Metab. 2017;102: 354-8.

52. Brown JP, Roux C, Törring O, et al. Discontinuation of denosumab and associated fracture incidence: analysis from the Fracture Reduction Evaluation of Denosumab in Osteoporosis Every 6 Months
(FREEDOM) trial. J Bone Miner Res. 2013;28: 746-52.

53. Bouxsein ML, Eastell R, Lui L-Y, et al. Change in bone density and reduction in fracture risk: a metaregression of published trials. J Bone Miner Res. 2019;34:632-42.

54. McClung MR. Cancel the denosumab holiday. Osteoporos Int. 2016;27:1677-82.

55. Anastasilakis AD, Papapoulos SE, Polyzos SA, Appelman-Dijkstra NM, Makras P. Zoledronate for the prevention of bone loss in women discontinuing denosumab treatment. A prospective 2-year clinical trial. J Bone Miner Res. 2019;34:2220-8.

56. Anastasilakis AD, Polyzos SA, Yavropoulou MP, Makras P. Combination and sequential treatment in women with postmenopausal osteoporosis. Expert Opin Pharmacother. 2020;21:477-90.

57. Everts-Graber J, Reichenbach S, Ziswiler HR, Studer $\mathrm{U}$, Lehmann T. A single infusion of zoledronate in postmenopausal women following denosumab discontinuation results in partial conservation of bone mass gains. J Bone Miner Res. 2020;35:1207-15.

58. Freemantle N, Satram-Hoang S, Tang E-T, et al. Final results of the DAPS (Denosumab Adherence Preference Satisfaction) study: a 24-month, randomized, crossover comparison with alendronate in postmenopausal women. Osteoporos Int. 2012;23:317-26.

59. Kendler D, Chines A, Clark $\mathrm{P}$, et al. Bone mineral density after transitioning from denosumab to alendronate. J Clin Endocrinol Metab. 2020;105: e255-64.

60. Sølling AS, Harsløf T, Langdahl B. Treatment with zoledronate subsequent to denosumab in osteoporosis: a randomized trial. J Bone Miner Res. 2020;35:1858-70.

61. van de Laarschot DM, McKenna MJ, Abrahamsen B, et al. Medical management of patients after atypical femur fractures: a systematic review and recommendations from the European Calcified Tissue Society. J Clin Endocrinol Metab. 2020;105: 1682-99.

62. Kwon Y-D, Kim D-Y. Role of teriparatide in medication-related osteonecrosis of the jaws (MRONJ). Dent J. 2016;4:41.

63. Khan AA, Morrison A, Kendler DL, et al. Case-based review of osteonecrosis of the jaw (ONJ) and application of the international recommendations for management from the International Task Force on ONJ. J Clin Densitom. 2017;20:8-24. 
64. Lai K-H, Chiang C-Y, Yang R-S, Yang K-C, Wu C-C. Conservative treatment of recurrent symptoms of an incomplete, atypical femoral fracture associated with glucocorticoid, bisphosphonate, and denosumab therapy in a patient with chronic obstructive pulmonary disease. Acta Clin Belg. 2019;74:370-4.

65. Cosman F, Crittenden DB, Ferrari S, et al. FRAME study: the foundation effect of building bone with 1 year of romosozumab leads to continued lower fracture risk after transition to denosumab. J Bone Miner Res. 2018;33:1219-26.

66. Lewiecki EM, Dinavahi RV, Lazaretti-Castro M, et al. One year of romosozumab followed by two years of denosumab maintains fracture risk reductions: results of the FRAME Extension study. J Bone Miner Res. 2019;34:419-28.

67. Leder BZ, Tsai JN, Uihlein AV, et al. Two years of denosumab and teriparatide administration in postmenopausal women with osteoporosis (the DATA Extension study): a randomized controlled trial. J Clin Endocrinol Metab. 2014;99:1694-700.

68. Tsai JN, Uihlein AV, Lee $H$, et al. Teriparatide and denosumab, alone or combined, in women with postmenopausal osteoporosis: the DATA study randomised trial. Lancet. 2013;382:50-6.

69. Leder BZ, Tsai JN, Uihlein AV, et al. Denosumab and teriparatide transitions in postmenopausal osteoporosis (the DATA-Switch study): extension of a randomised controlled trial. Lancet. 2015;386: 1147-55.

70. Cosman F, McMahon D, Dempster D, Nieves JW. Standard versus cyclic teriparatide and denosumab treatment for osteoporosis: a randomized trial. J Bone Miner Res. 2020;35:219-25.

71. Lyu H, Zhao SS, Yoshida K, et al. Comparison of teriparatide and denosumab in patients switching from long-term bisphosphonate use. J Clin Endocrinol Metab. 2019;104:5611-20.

72. Kendler DL, Bone HG, Massari F, et al. Bone mineral density gains with a second 12-month course of romosozumab therapy following placebo or denosumab. Osteoporos Int. 2019;30:2437-48.

73. Kanis JA, Harvey NC, McCloskey E, et al. Algorithm for the management of patients at low, high and very high risk of osteoporotic fractures. Osteoporos Int. 2020;31:1-12.

74. Shoback D, Rosen CJ, Black DM, Cheung AM, Murad MH, Eastell R. Pharmacological management of osteoporosis in postmenopausal women: an Endocrine Society guideline update. J Clin Endocrinol Metab. 2020;105:dgaa048. https://doi. org/10.1210/clinem/dgaa048.

75. Camacho PM, Petak SM, Binkley N, et al. American Association of Clinical Endocrinologists/American College of Endocrinology clinical practice guidelines for the diagnosis and treatment of postmenopausal osteoporosis-2020 update executive summary. Endocr Pract. 2020;26:564-70.

76. Ebina K, Hashimoto J, Kashii M, et al. The effects of switching daily teriparatide to oral bisphosphonates or denosumab in patients with primary osteoporosis. J Bone Miner Metab. 2017;35:91-8.

77. Saag KG, Petersen J, Brandi ML, et al. Romosozumab or alendronate for fracture prevention in women with osteoporosis. N Engl J Med. 2017;377: 1417-27.

78. Leder BZ, Tsai JN, Jiang LA, Lee H. Importance of prompt antiresorptive therapy in postmenopausal women discontinuing teriparatide or denosumab: the Denosumab and Teriparatide Follow-up study (DATA-Follow-up). Bone. 2017;98:54-8.

79. Ebina K, Hashimoto J, Kashii M, et al. Effects of follow-on therapy after denosumab discontinuation in patients with postmenopausal osteoporosis. Mod Rheumatol. 2021:31:485-492.

80. Makras P, Papapoulos SE, Polyzos SA, AppelmanDijkstra NM, Anastasilakis AD. The three-year effect of a single zoledronate infusion on bone mineral density and bone turnover markers following denosumab discontinuation in women with postmenopausal osteoporosis. Bone. 2020;138:115478.

81. Kondo H, Okimoto N, Yoshioka T, et al. Zoledronic acid sequential therapy could avoid disadvantages due to the discontinuation of less than 3-year denosumab treatment. J Bone Miner Metab. 2020: 38:894-902.

82. Comparative Antiresorptive Efficacy Discontinuation of Denosumab. https://clinicaltrials.gov/ct2/ show/NCT03623633. Accessed 2 Apr 2021.

83. Alendronate in an Weekly Effervescent Tablet Formulation Following Denosumab Discontinuation (BAD). https://clinicaltrials.gov/ct2/show/ NCT04338529. Accessed 2 Apr 2021.

84. Denosumab Sequential Therapy (DST). https:// clinicaltrials.gov/ct2/show/NCT03868033. Accessed 2 Apr 2021. 
85. Bisphosphonates for Prevention of Post-Denosumab Bone Loss. https://clinicaltrials.gov/ct2/ show/NCT03396315. Accessed 2 Apr 2021.

86. Preventing Osteoporosis Using Denosumab (PROUD). https://clinicaltrials.gov/ct2/show/ NCT02753283. Accessed 2 Apr 2021.
87. Examination of Efficacy and Safety of Other AntiResorption Drugs After 2-year-Denosumab Therapy in Japanese Osteoporosis Patients. https:// clinicaltrials.gov/ct2/show/NCT03755193. Accessed 2 Apr 2021. 